\title{
A monotematização da cobertura jornalística da Covid-19 no Jornal Nacional e Jornal da Record
}

\author{
Paulo Eduardo Silva Lins Cajazeira' \\ Cleide Luciane Antoniutti2 \\ José Jullian Gomes de Souza ${ }^{3}$ \\ Manoel Izidoro Cabral $\mathrm{Neto}^{4}$
}

\section{Resumo}

Este artigo tem como objetivo compreender os processos jornalísticos da cobertura da pandemia da Covid-19 pelo Jornal Nacional da TV Globo e Jornal da Record, da Record TV. O recorte temporal de análise iniciou-se em 18 janeiro a 15 de maio de 2020, direcionando a atenção jornalística para a construção de uma cobertura monotemática acerca da pandemia da Covid-19. Consideramos que esse processo de monotematização alterou não somente a cobertura em si, mas a audiência, bem como um apagamento de outros acontecimentos em razão dessa crise sanitária. Como método de pesquisa, procurou-se utilizar a pesquisa bibliográfica, a exploratória e a técnica da Análise de Conteúdo (AC), a partir das reportagens, a fim de verificar como as crises sanitárias e políticas se imbricaram e tornaram-se uma crise política de

\footnotetext{
1 Pós-doutor em Ciências da Comunicação pela Universidade da Beira Interior. Doutor em Comunicação e Semiótica pela PUC-SP. Professor do Curso de Jornalismo e do Mestrado em Biblioteconomia da Universidade Federal do Cariri. E-mail: paulo.cajazeira@ufca.edu.br

2 Pós-doutoranda em Comunicação pela Universidade Federal do Paraná. Doutora em Ciência da Informação pela Universidade Federal do Rio Janeiro/IBICT. Professora do Curso de Jornalismo da Universidade Federal do Cariri E-mail: luciane.antoniutti@ufca.edu.br

${ }_{3}^{3}$ Mestre em Biblioteconomia pela Universidade Federal do Cariri. E-mail: jullianjose64@gmail.com

${ }^{4}$ Mestrando em Biblioteconomia pela Universidade Federal do Cariri. E-mail: manoeelneeto@gmail.com
} 
saúde pública. Dessa forma, entendemos que a cobertura jornalística monotemática na TV alterou tanto a escolha pelas temáticas a serem evidenciadas nos telejornais, como a visualização de um telejornal com características de um programa jornalístico temático, a exemplo do Globo Repórter ou Repórter Record.

Palavras-chave: Cobertura jornalística. Covid-19. Telejornalismo

\section{The monothematization of Covid-19's news coverage in Jornal Nacional and Jornal da Record}

\section{Abstract}

This article aims to understand the journalistic processes of coverage of the Covid-19 pandemic by Jornal Nacional on TV Globo and Jornal da Record, on Record TV. The time frame for analysis began on January 18 to May 15, 2020, directing journalistic attention to the construction of a monothematic coverage of the Covid-19 pandemic. We believe that this monothematization process changed not only the coverage itself, but the audience, as well as an erasure of other events due to this health crisis. As a research method, we tried to use bibliographic, exploratory and Content Analysis (CA) techniques, based on the reports, in order to verify how the health and political crises intermingled and became a political crisis. public health. Thus, we understand that monothematic news coverage on TV has altered both the choice of themes to be shown on the news, as well as the viewing of a news program with the 
characteristics of a thematic journalistic program, such as Globo Repórter or Repórter Record.

Keywords: News coverage; Covid-19; Telejournalism

\section{Introdução}

Este artigo se propõe a analisar e discutir alguns aspectos da cobertura televisiva das maiores audiências do telejornalismo na televisão aberto, o Jornal Nacional e o Jornal da Record sobre a Covid-19 acerca dos processos de monotematização e as influências de temas políticos na cobertura da pandemia. A nossa análise de conteúdo começa em 18 de janeiro e se estende até o dia 15 de maio de 2020, considerado o período de exibição da primeira reportagem, as primeiras vítimas, o aumento no número de casos da doença e a disseminação global resultando na decisão da Organização Mundial da Saúde (OMS) em decretar pandemia do novo coronavírus chamado de Sars-Cov-2.

A relação da pandemia e a imprensa tem se mostrado monopolizadora, próxima e constante, conforme afirma o pesquisador Boaventura de Souza Santos (2020, p. 37-38) sobre o novo coronavírus:

Sabe cómo monopolizar la atención de los medios como el mejor experto en comunicación social. Descubrió nuestros hábitos y la proximidad social en la que vivimos para afectarnos más duramente. El coronavirus es nuestro contemporáneo en el sentido más profundo del término. No es solo porque es simultáneo, es decir, que ocurre en el mismo tiempo lineal que nuestras vidas.

Começamos o nosso estudo refletindo a respeito das relações do novo coronavírus e a contemporaneidade a partir das palavras do pesquisador português, Boaventura Santos, no artigo "El coronavírus y nuestra contemporaneidade", recémpublicado no livro Alerta Global: políticas, movimientos sociales y futuros em disputa en tiempos de pandemia. No período de análise da cobertura, as demais temáticas e assuntos não foram cobertas pelo telejornal, havendo apenas abordagens e ângulos acerca dos temas que perpassam a cobertura da Covid-19. Isso se configura como um momento único na cobertura jornalística do Jornal Nacional da TV Globo, que completou 
51 anos em 01 de setembro de 2020, e a televisão brasileira os seus 70 anos em 18 de setembro de 2020.

Segundo Maia (2007), a atual fase do JR iniciou no dia 30 de janeiro de 2006, exatamente um mês após a rescisão do contrato de Boris Casoy. A TV Record estreou às $20 \mathrm{~h} 40$ a nova e atual fase do Jornal da Record, livremente inspirado no Jornal Nacional da TV Globo. O telejornal tem apresentação dos jornalistas e ex-globais Celso Freitas que já foi apresentador do JN e Adriana Araújo $^{5}$, que trabalhava na TV Globo de Brasília DF. Atualmente, a Rede Record cobre $98 \%$ do território nacional e possui cinco emissoras próprias (nos estados de São Paulo, Rio de Janeiro, Brasília - DF, Minas Gerais e Pernambuco) e 92 afiliadas/repetidoras no restante do país (MAIA, 2007). O Jornal da Record - JR surgiu na década de 1980 com o intuito de ser o telejornal de rede da TV Record. Os primeiros apresentadores foram Paulo Markun e Silvia Poppovic.

Neste estudo, buscamos investigar de forma inicial o conceito de "monotematização" na cobertura jornalística em televisão, e os efeitos produzidos nas narrativas do telejornal. De acordo com o Dicionário Etimológico da Língua Portuguesa (2010), a palavra "mono" significa "único" e "tema" (do grego thema) corresponde a proposta, assunto. O seu contrário, a politematização, vem do grego poly "muitos". Assim. em linhas gerais, a monotematização é o ato ou efeito de tematizar, de usar um só tema, mesmo com enquadramentos diferentes. Já o formato politemático trabalha na perspectiva geralista, ao proporcionar uma vasta opção de temas do cotidiano ao público.

Conforme Dominique Wolton (1996, p. 111), “[...] os argumentos que se encontram no fundamento da televisão geralista são de duas ordens e, longe de estarem ultrapassados, eles, de fato, foram se reforçando ao longo dos anos". O primeiro diz respeito à televisão privada e enfatiza a lógica econômica: ao entrar em contato com o grande público, a televisão garante um vasto mercado e, consequentemente, grandes lucros, a partir de diversos temas e abordagens. Conforme o autor, "[...] se olharmos para os Estados Unidos, que inventaram a televisão geralista privada: é a ideia de que é também um fator de integração social e de identidade coletiva para um país, obedecendo sempre a lógica econômica" (WOLTON, 1996, p. 111).

\footnotetext{
${ }^{5} \mathrm{~A}$ jornalista e apresentadora deixou o telejornal em junho de 2020.
} 
Com o crescimento da Covid-19 no Brasil e no Mundo no primeiro semestre de 2020, a cobertura jornalística transformou-se em monotemática e híbrida, preocupada com aspectos sociais, econômicos, políticos e os índices de audiência, conforme o estudo mostrará ao longo da investigação. Deste modo, identificamos que no período enfocado para este estudo, a monotematização da cobertura jornalístico do Jornal Nacional (JN) e do Jornal da Record (JR) vai sendo constituída e apresentando picos de edições diárias que discorrem apenas sobre a Covid-19 - como será possível observar no momento da análise do objeto de estudo.

Dessa forma, buscamos analisar como a monotematização se apresentou na cobertura jornalística televisiva durante os meses de janeiro a maio de 2020 , mediante a observação da temática da Covid-19. O que possibilitou compreender como cada um dos telejornais estudados foi alterado por essa cobertura e como a sua audiência também foi sendo modificada ao longo dos meses.

\section{Cobertura telejornalística monotemática em tempos de pandemia da Covid-19}

O prefixo "mono" sugere a ideia de um, único, unidade e/ou unitário, ou seja, algo que está representado apenas por um determinado fator. No campo jornalístico, comumente, a cobertura de um telejornal é marcada pela presença de diversas e diferentes editorias: política, saúde, economia, esporte, cotidiano, moda entre outros. Com isso, compreendemos que, convencionalmente, um telejornal possui variados temas: politemático.

Todavia, no atual cenário ocasionado pela pandemia da Covid-19 visualizamos que na cobertura jornalística televisiva, especialmente nos telejornais "Jornal Nacional" e "Jornal da Record", durante os primeiros cinco meses de 2020, essa diversidade de temáticas foi sendo substituída por uma única temática acerca do novo coronavírus: a monotematização da cobertura jornalística sobre a Covid-19.

Assim, é pertinente e necessário compreendermos o que é essa monotematização frente a cobertura jornalística em 2020, seus efeitos e como ela foi sendo construída ao longo da descoberta do vírus na China, a sua chegada no Brasil até o pronunciamento da OMS, em 11 de março, acerca do início de uma pandemia. Diante desse quadro, 
entendemos num primeiro momento, que há uma mudança significativa no fazer telejornalístico, pois as temáticas versam, de um modo geral, apenas sobre a Covid-19.

Desse modo, é pertinente compreendemos o conceito de cobertura telejornalística pelas acepções mais comuns e tradicionais da área televisiva. Cobertura corresponde ao trabalho de reportagem a ser realizado no local da ocorrência dos fatos a serem noticiados. Ou ainda, numa conceituação mais técnica, que indica a cobertura como área de cobertura, que se define pelo espaço geográfico ou de abrangência, espaço recoberto ou alcance de sinal de emissora (EMERIM; BRASIL, 2011).

Sobre o conceito de cobertura usual no jornalismo contemporâneo, Emerim e Brasil (2011, p. 4) explicam que "[...] na atualidade, é comum nas redações designar cobertura para praticamente todo o trabalho de reportagem que apresenta um tema sob diferentes abordagens, ou seja, que aprofunde, desenvolva ou diversifique o tema central". Este conceito de cobertura é o que se aproxima daquele que este trabalho se propõe em relação a como os telejornais da televisão aberta, o Jornal Nacional e o Jornal da Record, se propuseram a fazer sobre a Covid-19.

Entendemos a cobertura não só pelo aspecto conceitual, mas também pelo aspecto temporal. Quando o tema perdura por muito tempo nas pautas dos telejornais, ou pelos desdobramentos que o assunto ganha no decorrer de um período é que também pode ser chamado de grande cobertura. Assim,

\begin{abstract}
Uma grande cobertura pode remeter a um tipo de trabalho jornalístico que mostre um acontecimento em todas as suas perspectivas ou, pelo menos, as perspectivas possíveis de serem exibidas em televisão através da função jornalística. Uma cobertura grande, por sua vez, remeteria a um longo período de tempo em que este acontecimento permanecesse em pauta (EMERIM; BRASIL, p.4, 2011, grifos nossos).
\end{abstract}

No caso da Covid-19, pode-se afirmar que se trata de um tema diferenciado, que pela sua importância história mundial e desdobramentos e consequências, pode ser vista também como uma grande cobertura, já que perdura por muito tempo nas pautas dos veículos de comunicação como um acontecimento em todas as suas perspectivas, sem previsibilidade de término.

Neste sentido, Yvane Fechine (2001) diz que a televisão trabalha essencialmente com dois tipos de acontecimentos para serem recobertos. São eles os extratelevisivos, que ocorrem sem o planejamento da tevê como acidentes, catástrofes, imprevistos, 
pandemia e. também os televisivos que são produzidos pelas tevês como shows, eventos organizados para serem apresentados pela televisão.

Em acordo com tais tipologias, entendemos que a monotematização da cobertura jornalística sobre a Covid-19 é do tipo extratelevisiva. Os meios de comunicação, em especial a TV e o telejornalismo, não planejaram realizar uma cobertura como tem sido possível acompanhar desde janeiro de 2020 e, que foi sendo expandida ao longo dos meses seguintes. A construção da monotematização foi ocorrendo de forma gradual, à que medida que o novo coronavírus se alastrava pelo Brasil e pelo mundo e, se fez mais presente a cada dia nos lares brasileiros mediado pela televisão e pelo telejornalismo.

De certa forma, é possível inferir que essa monotematização na cobertura jornalística da televisão entre os meses de janeiro a maio, período de recorte da análise a seguir, implicou na invisibilidade de outros temas e problemas sociais. Pois, as notícias visualizadas na televisão estavam centradas em apresentar dados do aumento de casos de pessoas infectados, números de mortes, novos territórios pelos quais o vírus se espalhava, bem como o caos que a saúde brasileira, especificamente, estava enfrentando no atual momento.

\section{As recentes coberturas de crises de saúde no Brasil}

Antes de nos debruçarmos sobre a cobertura da Covid-19, buscamos identificar outras recentes coberturas jornalísticas de saúde, que em certa medida, tiveram proporções significativas na mídia e na sociedade. Ainda que não se configurem como coberturas monotemáticas, a exemplo do atual contexto, essas coberturas demonstram como o jornalismo e, mais especificamente o telejornalismo, discorre sobre essas crises sanitárias na sua história recente.

Uma das coberturas jornalísticas de saúde ocorreu na década de 1980, a partir do surgimento da Aids (1983 a 1987). As primeiras reportagens discorreram sobre a descoberta do vírus e o crescimento da então denominada "epidemia mais violenta do século", conforme informações da primeira reportagem sobre o tema "Primeiras informações ao público brasileiro sobre a Aids" realizada em 27 de março de 1983 pelo Fantástico e, durante a semana, pelo JN, conforme explicita o site Memória Globo. Porém, mesmo se configurando como uma temática nova e de interesse público, 
É preciso considerar que os arquivos de notícias não estão todos disponíveis, tornando complexa a categorização, precisamente sobre a quantidade e datas das abordagens dessa cobertura jornalística monotemática. Porém, o site Memória Globo informa que em $1^{\circ}$ de junho de 1987 foi descoberto um novo tipo do vírus - o terceiro tipo - sendo uma cobertura realizada pelo Jornal Nacional diretamente de Washington, capital dos EUA, de onde se acompanhava a reunião com 6 mil especialistas de 50 países, que discutiam sobre o tema.

Um segundo período de cobertura monotemática teve como protagonista a pandemia de Gripe H1N1 (2009). O surto da Influenza A/H1N1 transformou-se na primeira pandemia do século XXI e matou mais de 2 mil pessoas no País, como destaca o site Memória Globo. No dia 24 de abril de 2009, o telejornal destacou que o vírus da gripe H1N1 estava chegando ao território dos EUA, depois de matar 20 pessoas no México, sendo esta a primeira notícia sobre a doença, citada no Brasil. Já no dia seguinte, 25 de abril, uma nova reportagem anunciava que o Ministério da Saúde criou um gabinete para lidar com casos da gripe H1N1.

Em seguida, o telejornal destacou uma notícia, em 27 de abril, acerca da chegada de duas pessoas no Brasil que vieram do México e que estavam internadas em Belo Horizonte, sob suspeita de terem contraído o vírus. Em São Paulo, outra pessoa apresentava sintomas, cujo resultado ainda não era confirmado.

Um terceiro momento monotemático na cobertura jornalística sobre saúde, ocorreu no ano de 2015, cujo tema era a microcefalia. Para discorrermos sobre essa cobertura, faz-se preciso destacar que ela ocorre ao mesmo tempo em que se constata a existência de uma epidemia de dengue no Brasil, noticiada pelo telejornal em 14 de maio de 2015. Em seguida, no dia 22 de maio, o JN noticiou que a cidade de São Paulo registrava o primeiro caso de Zika vírus. Já em 22 de julho, a cobertura destacava os criadouros de Aedes Aegypti (inseto transmissor da dengue e o Zika vírus) em obras que deveriam ter sido entregues para a Copa do Mundo do Brasil em 2014.

Contudo, mesmo diante dessas coberturas os telejornais não demonstraram mudanças significativas e impactantes em seus noticiários. $\mathrm{O}$ caráter politemático da cobertura continuou a ser identificado, o que diferente da cobertura que vem sendo observado em 2020, ao mesmo nos primeiros meses desse ano. 


\section{Procedimentos metodológicos}

A metodologia adotada para o presente estudo tem natureza aplicada e perpassa a abordagem quantiqualitativa, objetivando tanto a análise numérica quanto as causas e motivações do fenômeno pesquisado. De acordo com Minayo e Sanches (1993, p. 247) "[...] é de se desejar que as relações sociais possam ser analisadas em seus aspectos mais 'ecológicos' e 'concretos' e aprofundadas em seus significados mais essenciais". Diante do entrelaçamento destas abordagens, poderemos identificar e explicar o processo de cobertura jornalística do Jornal Nacional e do Jornal da Record acerca da Covid-19.

Enquanto estratégia de investigação, foi utilizada a pesquisa exploratória-descritiva com a finalidade de compreender a relação entre jornalismo e saúde, referente às coberturas jornalísticas monotemáticas no histórico JN e JR. Para Richardson (2011), este modelo de pesquisa tem como objetivo a familiarização com o tema e a descrição sistemática do fenômeno de modo objetivo e detalhado. Também foram utilizadas a pesquisa bibliográfica sobre a monotematização e as coberturas jornalísticas sobre saúde e pandemias.

A análise dos dados obtidos ocorreu através do uso da Análise de Conteúdo (AC). De acordo com Bardin (2016), a AC funciona tanto como um método de pesquisa, quanto uma técnica de análise. Conforme uso da $A C$ enquanto técnica de análise, a autora destaca a importância da criação de categorias, que na presente pesquisa se caracterizam a partir das reportagens que versavam sobre a temática da Covid-19. Para essa categorização, as reportagens foram selecionadas segundo o uso das palavraschave (pandemia, Covid-19 e novo coronavírus) identificadas no título das reportagens ou no texto de apresentação. Posteriormente, as reportagens foram organizadas por mês (entre janeiro e maio de 2020), para que fosse possível identificar como a monotematização se apresentada durante a cobertura do JN e do JR.

O objeto de estudo é a cobertura jornalística da pandemia da Covid-19, que vem sendo realizada pelo JN e JR no ano de 2020. O JN é o principal telejornal do País, e ao longo dos seus mais de 50 anos de existência se firma como um dos líderes de audiência no horário nobre da televisão brasileira, seguido do Jornal da Record. E, acerca da atual cobertura jornalística na TV, vem demonstrando aspectos e mudanças interessantes que 
necessitam de uma investigação em caráter científico, enquanto forma de corroborar para a compreensão deste cenário jornalístico.

O período de análise foi delimitado de 18 de janeiro a 15 de maio de 2020 , diante da identificação da primeira notícia sobre o surgimento do coronavírus na China e, em seguida, do avanço do coronavírus pelo mundo e sua chegada ao Brasil. O corpus de análise é composto por reportagens do JN com a temática da Covid-19, que foram coletadas no aplicativo Globoplay, totalizando 909 reportagens no período de análise. Também utilizamos o site Memória Globo, para coletar informações sobre a linha do tempo, a partir da datificação de coberturas de saúde no JN. Assim, os dados analisados foram tabulados e apresentados graficamente. A coleta de dados do Jornal da Record ocorreu a partir do site do telejornal, com a delimitação do mesmo período do JN, 18 de janeiro a 15 de maio de 2020, totalizando um total de 1021 reportagens sobre a Covid19.

A partir desses dados será possível realizar uma comparação acerca dessa cobertura e da ideia sobre a monotematização nesse atual momento do telejornalismo sobre a Covid-19, mediante a observação do Jornal Nacional e do Jornal da Record ambos, se apresentando como os principais telejornais de suas respectivas emissoras e também do Brasil. E, compreender como essa cobertura monotemática foi sendo construída ao longo dos primeiros meses de 2020.

\section{Análise da cobertura jornalística do Jornal Nacional}

Nesta perspectiva, tratando especificamente da atual cobertura jornalística monotemática da Covid-19 realizada pelo Jornal Nacional, notamos um aumento significativo nos meses de março e abril de 2020 , frente ao período de análise, quando foi iniciado o distanciamento e isolamento social no Brasil. Sobre a temática da Covid-19, os números de reportagens quase quintuplicaram no mês de março (322), em comparação ao mês de fevereiro (70), como pode ser visualizado na tabela a seguir: 
Tabela 1 - Quantidade de reportagens sobre a Covid-19 no Jornal Nacional

\begin{tabular}{|c|c|}
\hline Mês & № de reportagens \\
\hline Janeiro & 23 \\
\hline Fevereiro & 70 \\
\hline Março & 322 \\
\hline Abril & 331 \\
\hline Maio & 165 \\
\hline
\end{tabular}

Fonte: Elaboração própria (2020).

Assim, constatamos que a temática da pandemia atual, no ano de 2020, exerceu certa predominância nas reportagens do JN. Anteriormente, o telejornal compreendia uma ampla gama de temas tais como saúde, educação, política, cotidiano, esportes e acontecimentos na vida das celebridades. Contudo, conforme a referida pandemia chegava ao mundo ocidental, especialmente às Américas, houve a mudança de uma politematização para uma monotematização ocasionada pela Covid-19.

Conforme a Tabela 1 evidencia, houve um aumento de mais de $300 \%$ entre o primeiro e o segundo mês de análise. Já entre fevereiro a abril, visualizamos um aumento de quase $500 \%$ em relação ao período inicial. Para efeitos de análise, encara-se que no mês de abril houve o ápice da monotematização do telejornal, ou seja, encara-se o fenômeno de forma segmentada e não de forma absoluta e indivisível. De fato, trata-se de um momento de uma cobertura monotemática - como já visualizado em outros momentos, mas de forma mais acentuada -, precedido e seguido de uma forte predominância da temática da Covid-19 nas reportagens do Jornal Nacional.

No mês de abril, a monotematização das notícias continuou em crescimento, totalizando 331 reportagens como mostra o Gráfico 1, a seguir:

Gráfico 1 - Crescimento da monotematização da cobertura noticiosa do Jornal Nacional

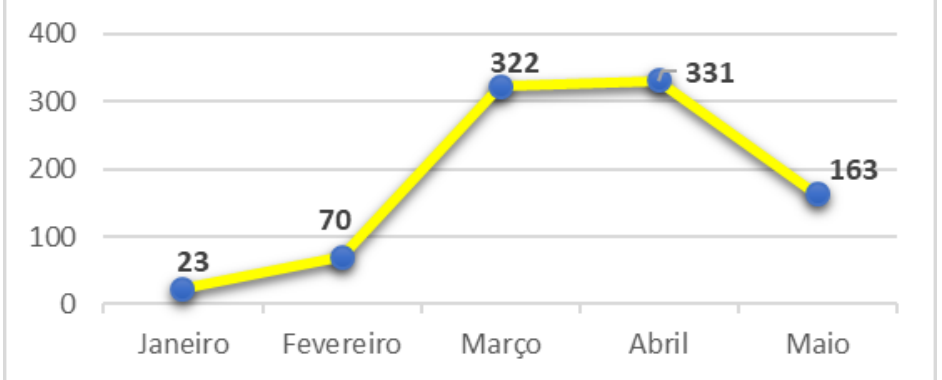

Fonte: Elaboração própria (2020). 
Identificamos que é a partir do dia 13 de março que a curva desponta para a cobertura jornalística com mais de $50 \%$ do telejornal dedicado a cobrir a temática da Covid-19. Essa porcentagem representa, por exemplo, que dentre 25 reportagens diárias do JN no mês de março, mais da metade era dedicada ao tema da Covid-19. Assim, no período correspondente entre 18 de março a 13 abril tem-se alguns picos no número de reportagens, totalizando 386 reportagens dedicadas à Covid-19. O pico diário máximo é identificado na seguinte ordem: 13 de abril (24); 19 de março (23); 24 e 28 de março (22); 18 de março e 11 de abril (21) e; os dias $1^{\circ}$ e 9 de abril (20).

É importante ressaltar que a partir do dia 24 de abril, observamos um decréscimo da quantidade de reportagens sobre a Covid-19, mas se comparado com o início da cobertura no mês de janeiro ainda é um volume superior com média de 8 a 12 reportagens. Ainda que a curva comece a demonstrar uma queda no mês de maio, é preciso considerar que a coleta dos dados ocorreu apenas até o dia 15, ou seja, metade do mês de maio. Observamos, também, que entre os meses de abril e maio o número de reportagens decaiu pela metade, aproximadamente (de 331 para 163). Assim, esse número pode ser superior ou representar uma diminuição da monotematização na cobertura jornalística do JN.

Acerca da sua audiência, no período de 13 de janeiro a 15 de maio de 2020, percebe-se que o JN teve alguns picos de maior audiência, como observado nos seguintes períodos: de 20 a 26 de janeiro $(30,1)$; de 16 a 22 de março $(34,2)$; de 23 a 29 de março $(33,1)$; de 30 de março a 5 de abril $(30,3)$ e de 20 a 26 de abril $(30,2)$. E nos outros períodos se manteve com média entre 28 e 29 pontos de audiência. Numa breve comparação visualizamos que a média de audiência anterior à pandemia era de 26 pontos, ou seja, há um aumento significativo.

O aumento da audiência da primeira semana (20 a 26 de janeiro) está associado às primeiras reportagens sobre o coronavírus na China, representando um total de 13 reportagens. No segundo período analisado (16 a 22 de março), a Organização Mundial da Saúde (OMS) já havia classificado o novo coronavírus como pandemia, em 11 de março, e já era possível visualizar no Brasil mais de 1000 casos do novo coronavírus.

No período de 23 a 29 de março, o noticiário do JN apresentou dados sobre o aumento de casos da Covid-19, representando mais de 4.500 casos de pessoas com o 
vírus e mais de 150 mortes no Brasil. Ou seja, com a situação cada vez maís alarmante e a cobertura jornalística sendo intensificada, pode-se atribuir o aumento da audiência ao interesse do público em se atualizar sobre os dados e compreender as medidas que estavam sendo feitas pelo governo. Posteriormente, outro pico de audiência foi registrado entre 30 de março a 5 de abril. Neste período, os dados sobre a incidência da Covid-19 no Brasil já revelavam mais de 500 mortes, ou seja, quase $40 \%$ a mais e mais de 12 mil infectados, cerca de $30 \%$ a mais do que no período anterior.

O tempo de duração do telejornal também foi sendo estendido, conforme as notícias sobre a Covid-19 ganhavam maiores proporções. Assim, percebemos que há todo um rearranjo no telejornal que impacta tanto na duração, na monotematização e também na duração e cobertura do telejornal.

\section{Análise da cobertura jornalística do Jornal da Record}

A cobertura do Jornal da Record sobre a Covid-19, no mesmo período do JN, apresentou um total de 1021 reportagens, ou seja, 112 reportagens a mais, o que corresponde à $44 \%$ do total. De início, a quinzena final de janeiro inicia o recorte temporal de análise com poucas pautas voltadas à questão pandêmica. Assim, em meados de fevereiro, a cobertura ainda foi tímida, com 17\% do espaço total nas edições do jornal durante o mês. Contudo, nos meses posteriores, a cobertura se intensificou, chegando até a ocupar $64 \%$ do quantitativo total de pautas do jornal, como foi o caso do mês de abril (Tabela 3):

Tabela 2 - Cobertura da pandemia da Covid-19 no Jornal da Record de janeiro a maio de 2020

\begin{tabular}{|c|c|c|c|}
\hline Mês & Total de pautas & Pautas Covid-19 & $\%$ \\
\hline Janeiro & 260 & 20 & 7 \\
\hline Fevereiro & 433 & 75 & 17 \\
\hline Março & 591 & 333 & 56 \\
\hline Abril & 651 & 421 & 64 \\
\hline Maio & 355 & 172 & 48 \\
\hline Total & 2290 & 1021 & 44 \\
\hline
\end{tabular}

Fonte: Elaboração própria (2020).

O segundo telejornal no Brasil com maior audiência é o Jornal da Record (JR) e que também desempenha um papel importante na TV brasileira. Em pesquisa e análise, 
comparando a monotematização das notícias sobre a Covid-19 nos dois telejornais, os números de reportagens exibidas no primeiro semestre são distintos. Notou-se que no JN o número de reportagens exibidas entre o mês de março e abril ultrapassaram os $80 \%$ do telejornal e no JR ficou entre os 50\% e 60\%. Ambos exibiram assuntos sobre a pandemia, mas houve essa discrepância onde a monotematização foi mais evidente no JN em comparação ao JR. Ou seja, a cobertura do JR ocorreu normalmente com a apresentação de notícias com temáticas variadas.

Desse modo, no Gráfico 2 é possível observar como deu-se o crescimento da temática da Covid-19 no JR, a partir do período de análise recortado para este estudo:

Gráfico 2 - Crescimento da monotematização da cobertura do Jornal da Record

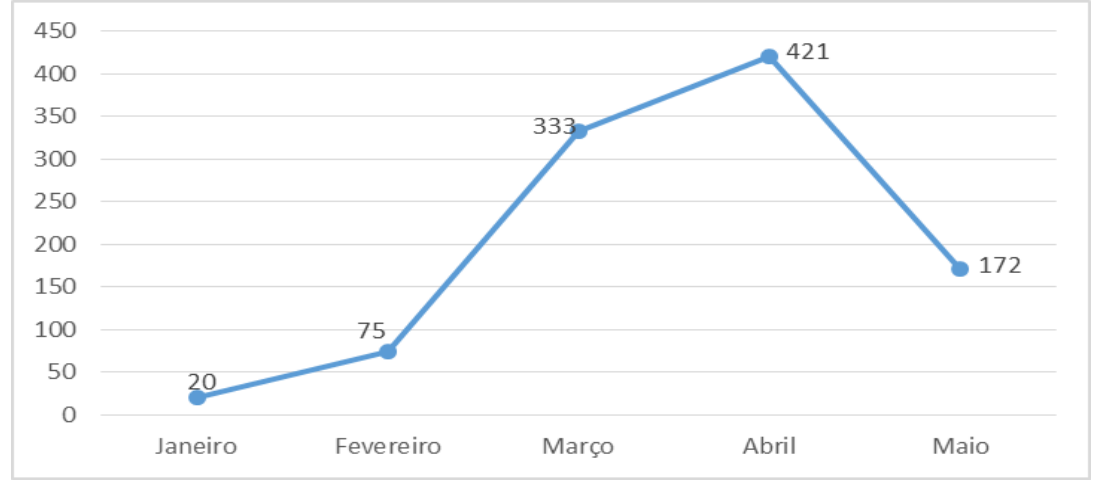

Fonte: Elaboração prórpia (2020).

De acordo com o Gráfico 2, o JR apresenta um crescimento de reportagens sobre a Covid-19 superior ao do JN. Numa comparação entre os telejornais temos os seguintes dados: o JN tem como pico 331 reportagens sobre a Covid-19 em abril, e o JR 421. Ou seja, são 90 reportagens a mais realizadas pelo $\mathrm{JN}$ demonstrando que a monotematização é superior no telejornal da Record TV. Esse fato, pode ajudar a explicar um dos motivos para que a audiência do JR tenha aumentado no período analisado. Antes da pandemia, o telejornal obtinha cerca de 4 pontos de audiência e durante essa cobertura jornalístico marcou cerca de 7 pontos. Contudo, ainda continua na viceliderança em comparação com o JN.

Esse aumento também pode ser visualizado no mês de maio. O JN apresentou 163 e o JR 172. Apesar da pouca diferença o JR continua à frente do principal telejornal na Rede Globo e do Brasil. Nessa vertente, também objetivamos analisar os impactos de 
tal monotematização na audiência do telejornal. Optamos por apresentar os dados da audiência de cada telejornal, por semana, a partir dos números disponibilizados pela Kantar Ibope Media. É importante destacar que, para cada um ponto de audiência, é considerado 70.559 mil domicílios sintonizados no programa; ou fazendo-se a contagem individual, cada um ponto de audiência equivale a 199.309 pessoas sintonizadas.

Tabela 3 - Audiência do Jornal Nacional e Jornal da Record entre janeiro e maio de 2020

\begin{tabular}{|c|c|c|}
\hline Data & JN & JR \\
\hline 13/01 a $19 / 01$ & 29,1 & 7,1 \\
\hline 20/01 a $26 / 01$ & 30,1 & 7,4 \\
\hline 27/01 a 02/02 & 28,4 & 7,8 \\
\hline 03/02 a 09/02 & 28,2 & 8,3 \\
\hline 10/02 a 16/02 & 29,8 & 8,5 \\
\hline 17/02 a 23/03 & 28,3 & 8,2 \\
\hline 24/03 a 01/03 & 28,5 & 8,4 \\
\hline 02/03 a 09/03 & 29,0 & 8,4 \\
\hline 09/03 a 15/03 & 29,3 & 8,2 \\
\hline 16/03 a 22/03 & 34,2 & 9,3 \\
\hline 23/03 a 29/03 & 33,1 & 10,0 \\
\hline 30/03 a 05/04 & 30,3 & 9,6 \\
\hline 06/04 a 12/04 & 29,1 & 9,2 \\
\hline $13 / 04$ a 19/04 & 29,7 & 9,3 \\
\hline 20/04 a 26/04 & 30,2 & 8,7 \\
\hline 27/04 a 03/05 & 29,4 & 8,3 \\
\hline 04/05 a 10/05 & 29,2 & 8,4 \\
\hline $11 / 05$ a 17/05 & 29,3 & 8,3 \\
\hline
\end{tabular}

Fonte: kantar Ibope (2020)

A cobertura jornalística do Jornal Nacional e Jornal da Record foi se tornando monotemática a partir da preocupação de organizações como a OMS e o desconhecimento sobre os efeitos do vírus, as formas de contágios e as orientações sanitárias com seus devidos cuidados. Assim, desde o mês de janeiro, o JN e JR noticiaram alguns informes sobre o surgimento do novo coronavírus, mas sem grandes alardes por ser um caso ainda restrito na cidade chinesa de Wuhan.

Contudo, à medida que os casos de pessoas infectadas e de mortes foram crescendo no cenário internacional e de expandido pelo Oriente e pela Europa, os noticiários demonstraram maior interesse por noticiar. Uma vez que a Covid-19 chega ao Brasil, os telejornais também começam a intensificar as notícias sobre o novo coronavírus. Desse forma, é que visualizamos a construção de uma cobertura 
monotemática, mas, aparentemente, que ocorreu de forma natural. Visto que, é um fenômeno que novo, que modificou os hábitos, costumes, rotinas e as próprias relações pessoais.

Assim, a programação do $\mathrm{JN}$ e do $\mathrm{JR}$ na cobertura passou por um processo de noticiabilidade referente ao quantitativo de reportagens sobre o mesmo acontecimento em um único local (telejornal) em que se preza tradicionalmente pela pluralidade de informações simbólicas, testemunhais e dramáticas. Este estudo propôs uma reflexão sobre o tema único na cobertura da pandemia do novo coronavírus e o impacto das crises políticas na rotina do telejornal. Entendemos que o discurso monotemático se sustentou dentro de um quadro inalterado de domínio, articulado pelo destinador em relação ao destinatário.

Os dados coletados, analisados e apresentados neste estudo demonstram que, a monotematização da cobertura jornalística, durante os primeiros meses de 2020, mostrouse expressiva com a identificação de recursos de mediação utilizados na cobertura da pandemia em ambos os telejornais. O que sugere, também, que o telespectador, no início da pandemia, estava interessado em se informar sobre os acontecimentos acerca da Covid-19, que por sua vez se apresentou como um fenômeno novo na história, acarretando em isolamento social, uso de materiais de equipamento para proteção individual e uma transformação radical nos hábitos cotidianos. Assim, o telejornalismo vem cumprindo um dos seus principais pilares: 0 ato de informar a sociedade.

\section{Considerações Finais}

Ao debruçarmos sobre a cobertura monotemática dos principais telejornais da Rede Globo e da Record TV, Jornal Nacional e Jornal da Record, identificamos que a partir do dia 18 de janeiro até 15 de maio, período analisado, ambos os telejornais foram sofrendo uma significativa mudança nas suas pautas cotidianas. De uma cobertura politemática, com a presença e a marca da diversidade de temáticas abordados num telejornal, a audiência passou a observar reportagens que versavam apenas sobre um único eixo: a Covid-19.

Com isso, é possível falarmos sobre uma cobertura monotemática diferentemente de tudo o que a sociedade está acostumada a acompanhar ao ligar a televisão e 
acompanhar os noticiários. Essa monotematização se configura como um momento novo no telejornalismo, fazendo com que outros problemas, mazelas sociais e acontecimentos que não perpassam, em algum ponto, pela Covid-19 não seja noticiados. Ou seja, há uma evidente transformação no critério de noticiabilidade tanto do JN como do JR.

O fenômeno da monotematização também modificou os números da audiência de ambos os telejornais. O JN continuou a ser o telejornal mais assistido do Brasil, aumentando a sua audiência em cerca de 3 até 5 pontos; já o JR teve um crescimento na audiência entre 4 pontos a mais do que de costume, se mantendo na vice-liderança. Também foi possível identificar que o JR foi um telejornal com cobertura mais monotemática do que o JN, como apresentado na comparação entre os gráficos 1 e 2 .

Com a Tabela 2, acerca da audiência entre os dois telejornais, o JR apresenta maior crescimento da audiência entre janeiro e maio. $O \mathrm{JR}$ tinha em janeiro 7 pontos de audiência, aumentando para 8,3, pico de 10 e se mantendo com média de 8 pontos. Já o $\mathrm{JN}$, mesmo sendo o mais assistido, não demonstrou uma significativa mudança na audiência no período analisado. Assim, manteve a sua audiência de forma constante entre 29 pontos. Os dados do JN, só apresentam aumento quando comparados com o mesmo período do ano anterior, 2019, despontando para cerca de 3 a 5 pontos a mais na audiência com a cobertura da Covid-19.

Neste sentido, entendemos que a cobertura jornalística monotemática na TV alterou tanto a escolha pelas temáticas a serem evidenciadas nos telejornais, como a visualização de um telejornal com características de um programa jornalístico temático, a exemplo do Globo Repórter ou Repórter Record.

\section{Referências}

BARDIN, Laurence. Análise de conteúdo. Tradução de Luís Antero Reto e Augusto Pinheiro. São Paulo: Edições 70, 2016.

EMERIM, Cárlida. BRASIL, Antônio. Coberturas em Telejornalismo. In: CONGRESSO BRASILEIRO DE CIÊNCIAS DA COMUNICAÇÃO, 34., 2011. Anais [...], Recife, 2011. Disponível em: http://www.intercom.org.br/papers/nacionais/2011/resumos/R6-1276-1.pdf. Acesso em 17 nov. 2020.

FECHINE, Yvana. Televisão e presença. São Paulo: Estação das Letras, 2008.

GLOBOPLAY. Jornal Nacional. [s/d]. Disponível em: <https://globoplay.globo.com/jornalnacional/t/MyCrVrr6gW/>. Acesso em: 6 set. 2020. 
KANTAR IBOPE MEDIA. Audiência do Jornal Nacional. 2020. Disponível em: https://www.kantaribopemedia.com/. Acesso em: 6 set. 2020.

MAIA, Wander Veroni. Edição no Jornal Nacional e Jornal da Record: uma análise comparativa a partir dos critérios de noticiabilidade dos telejornais de rede. Trabalho de conclusão de curso de Jornalismo do Centro Universitário de Belo Horizonte. Belo Horizonte, 2007. P. 24 - 26. Disponível em: <http://www.bocc.ubi.pt/pag/maia-wanderedicao-jornal-nacional-jornal-record.pdf > Acesso em 26 jun. 2020.

MEMÓRIA GLOBO. Jornal Nacional. [s/d]. Disponível em: https://memoriaglobo.globo.com/jornalismo/jornalismo-e-telejornais/jornal-nacional/. Acesso em: 6 set. 2020.

MINAYO, Maria Cecília S.; SANCHES, Odécio. Quantitativo-qualitativo: oposição ou complementaridade? Cadernos de Saúde Pública, Rio de Janeiro, v. 9, n. 3, p. 239-262, jul./set., 1993.

RICHARDSON, Roberto Jarry. Pesquisa social: métodos e técnicas. 3. ed. São Paulo: Atlas, 2011.

SANTOS, Boaventura S. El corononavirus y nuestra contemporaneidade. In: KASSIR et al. Alerta global: políticas, movimentos sociales y futuros en disputa en tiempos de pandemia. Buenos Aires: CLACSO; Lima: ALAS, 2020, p. 35-40.

WOLTON, Dominique. Elogio do grande público: uma teoria crítica da televisão. São Paulo: Editora Ática, 1996.

Envio: 1 out. 2020

Aceite: 2 out. 2020 